
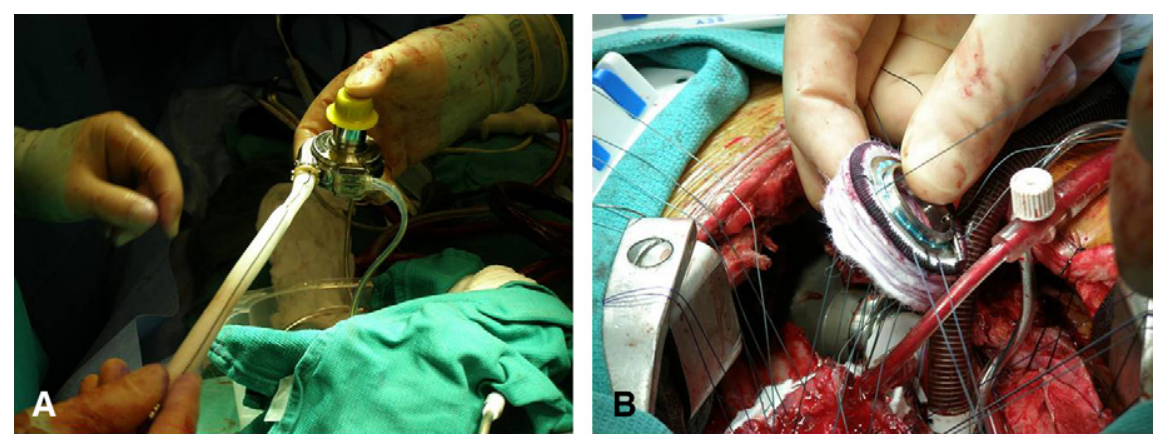

FIGURE 2. A, Outflow graft is restricted close to the HeartWare HVAD (arrow). B, Additional felt rings are used to decrease the intracavitary length of the inflow cannula.

pump speed to approach the lower operating limit of 1800 rpm. Implications include (1) lower accuracy of estimated flow at lower speeds, (2) less ability to correct suction conditions by lowering pump speed, and (3) increased potential for pump thrombosis or rotor instability. Second, the HeartWare HVAD inflow cannula length was designed for placement through the left ventricular apex and is not optimized for the right ventricle. Shortening the length of the inflow cannula to accommodate the shallower right ventricular cavity in the right ventricular outflow tract is achieved by placing additional felt rings under the fixation ring (Figure 2, B). Other locations that may potentially allow normal chest closure include placement into the right atrium or the diaphragmatic surface of the right ventricle.

For this patient, the goals for pump flows were 3 to $4 \mathrm{~L} / \mathrm{min}$ through the RVAD and 5 to $6 \mathrm{~L} / \mathrm{min}$ through the LVAD. Anticoagulation strategy consisted of aspirin and warfarin sodium, with an international normalized ratio goal of 2 to 3 . We were successful in this case; however, this is the first report of HeartWare HVAD use in the role of RAVD after HeartMate II implantation. Firm recommendations regarding the potential widespread applicability of this therapy are therefore limited.

\section{References}

1. Potapov EV, Loforte A, Weng Y, Jurmann M, Pasic M, Drews T, et al. Experience with over 1000 implanted ventricular assist devices. J Card Surg. 2008;23: 185-94.

2. Hetzer R, Krabatsch T, Stepanenko A, Hennig E, Potapov EV. Long-term biventricular support with the HeartWare implantable continuous flow pump. J Heart Lung Transplant. 2010;29:822-4.

3. Frazier OH, Myers TJ, Gregoric I. Biventricular assistance with the Jarvik FlowMaker: a case report. J Thorac Cardiovasc Surg. 2004;128:625-6.

\title{
Complete resection of asymptomatic solitary right atrial metastasis from renal cell carcinoma without inferior vena cava involvement
}

\author{
Narihiro Ishida, MD, PhD, Hirofumi Takemura, MD, PhD, Katsuya Shimabukuro, MD, PhD, and \\ Yukihiro Matsuno, MD, PhD, Gifu, Japan
}

Metastatic cardiac tumors are considered a terminal state of primary malignancy. Therefore, the condition of patients, local recurrence, and other metastases should be considered regarding indications for surgery, which should aim to

From the Department of General and Cardiothoracic Surgery, Graduate School of Medicine, Gifu University, Gifu, Japan.

Disclosures: Authors have nothing to disclose with regard to commercial support.

Received for publication April 1, 2011; accepted for publication April 18, 2011; available ahead of print May 19, 2011.

Address for reprints: Narihiro Ishida, MD, PhD, 1-1 Yanagido, Gifu City, Gifu 501-1194, Japan (E-mail: Alpineskierjp@aol.com).

J Thorac Cardiovasc Surg 2011;142:e142-4

$0022-5223 / \$ 36.00$

Copyright (c) 2011 by The American Association for Thoracic Surgery

doi:10.1016/j.jtcvs.2011.04.020 improve the prognosis of patients in good condition with malignancies and prevent concomitant critical events.

\section{CLINICAL SUMMARY}

A 61-year-old woman was referred to the Graduate School of Medicine with an incidentally discovered right atrial tumor. She had undergone radiotherapy and chemotherapy to treat bone metastasis after left nephrectomy for renal cell carcinoma and radical hysterectomy for uterine endometrial adenocarcinoma 1 year previously and was free of symptoms originating from the heart. A computed tomography examination for femoral pain revealed a cardiac tumor (Figure 1,A) without findings in the femur. Subsequent 


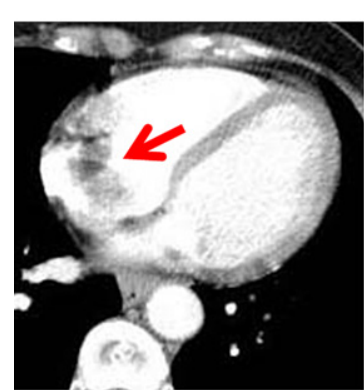

A

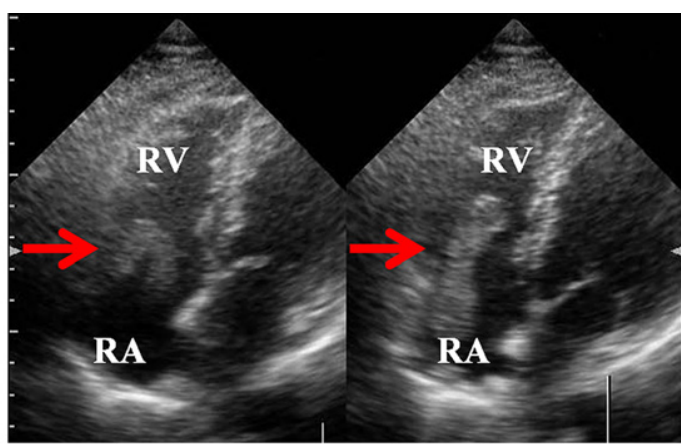

B systolic phase diastolic phase

FIGURE 1. Preoperative enhanced computed tomography and echocardiography. A, Enhanced computed tomography shows solitary right atrial tumor arising from right atrial appendage (arrow). B, Echocardiography shows solitary right atrial tumor (arrow) entering right ventricle during diastolic phase and returning inside right atrium during systolic phase. $R A$, Right atrium; $R V$, right ventricle.

echocardiography revealed a solitary right atrial tumor that arose from the right atrial appendage and entered the right ventricle during the diastolic phase and returned into the right atrium during the systolic phase (Figure 1, B). A physical examination and diagnostic imaging did not reveal any local recurrence or other metastases.

The right atrial tumor was surgically resected to prevent sudden death caused by pulmonary embolism resulting from tumor separation. The ascending aorta, superior vena cava, and inferior vena cava from the right atrium were cannulated via a median sternotomy, and then a cardiopulmonary bypass was established. Tumor tissue occupied the entire right atrial appendage and proceeded into the cardiac cavity (Figure 2, A). The cylindric tumor appeared cracked and likely to imminently detach (Figure 2, B). The tumor was completely resected with the right atrial appendage, and the defect was reconstructed using an equine pericardial patch under cardiac arrest with cardiopulmonary bypass (Figure 2, $C$ ). The margin of the resection was cryoablated to confirm complete resection.

A pathologic assessment of the tumor revealed clear cell carcinoma that was diagnosed as kidney metastasis. The surgical margin and pericardiac effusion remained free of malignancy.

The patient tolerated all procedures and was discharged without complications. She has remained well without recurrence or metastasis for 12 months since the procedure.

\section{DISCUSSION}

Surgery for cardiac metastasis from renal cell carcinoma with inferior vena cava involvement is often described as complete resection with the inferior vena cava. Martínez-Salamanca and colleagues ${ }^{1}$ described tumors
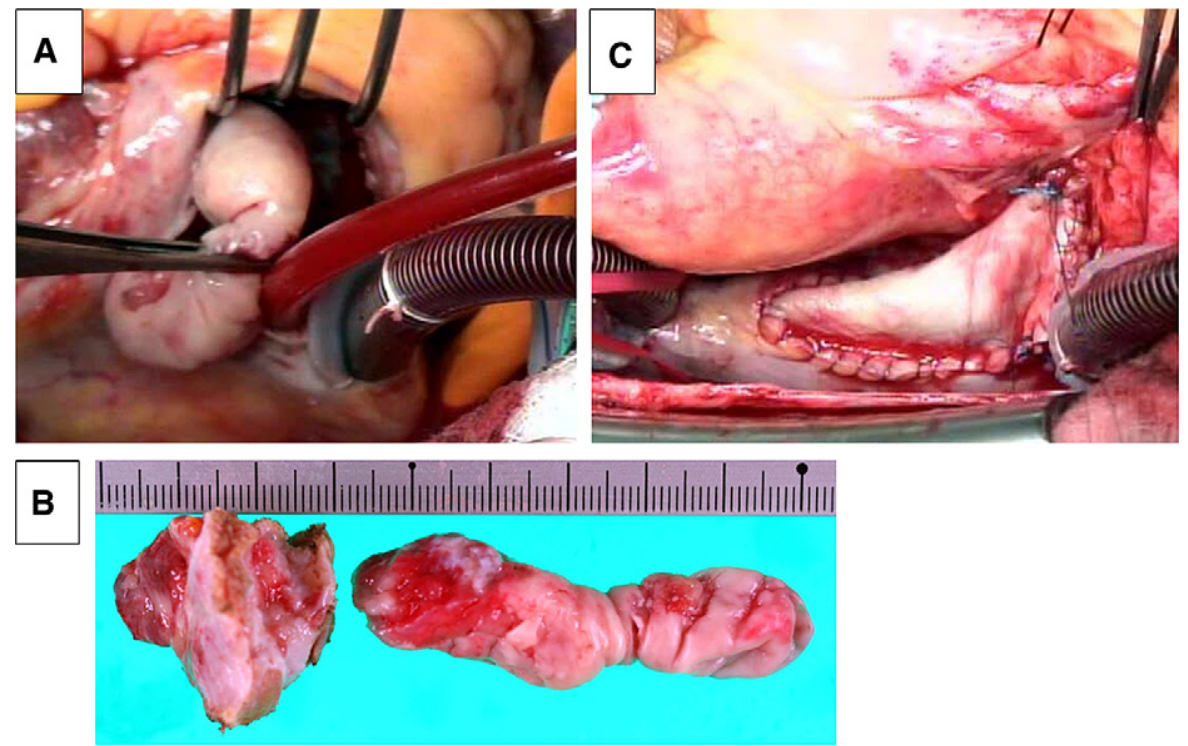

FIGURE 2. Details of tumor and resection. Cylindric tumor extending from right atrial appendage into cardiac cavity (A) appears cracked and likely to tear imminently (B). C, Complete resection of tumor with right atrial appendage and defect reconstructed with equine pericardial patch. 
extending into the atrium in 77 of 1122 patients with renal cancer who underwent radical nephrectomy and complete tumor thrombectomy between 1970 and 2006 at 11 US and European institutions.

On the other hand, cardiac metastasis from a renal cell carcinoma without inferior vena cava extension is rare, and thus surgical treatment for this condition is also rare.

One study of 11,432 autopsies found only $266(2.33 \%)$ cardiac tumors, and almost all of them were metastases originating from the lung, bone marrow, lymph node, and kidneys $(3 / 266,1.1 \%) .^{2}$ Another study of 114 autopsies found metastatic cardiac tumors originating from melanoma, germ cell, leukemia, and the kidneys $(12 / 114,11 \%){ }^{3}$

Zustovich and colleagues ${ }^{4}$ reviewed 15 patients who were surgically treated for cardiac metastasis from renal cell carcinoma without inferior vena cava involvement. Their review considered the following as pathologic routes of metastatic spread: a venous hematogenous pathway mainly to the right side of the heart and a lymphatic pathway to the lymph nodes, lungs, pericardium, and left side of the heart. ${ }^{4}$ Metastasis to the right side seemed relatively more frequent, especially to the right ventricle. Among the 15 patients in that review, the right ventricle was involved in 10 of 11 with metastasis to the right side. ${ }^{4}$

We found only 1 report of a solitary right atrial metastasis from renal cell carcinoma without inferior vena cava involvement, and this symptomatic patient died shortly after surgery. ${ }^{5}$ Because right atrial tumors generally elicit few symptoms during the early phase, complete surgical resection is likely to be difficult. However, an asymptomatic right atrial tumor that was incidentally detected in our patient was metastasis that could be resected. This is the first report of a favorable outcome after complete surgical resection of a right atrial metastasis from renal cell carcinoma.

\section{CONCLUSIONS}

Progress in diagnostic imaging allows early diagnosis of not only symptomatic but also asymptomatic metastatic cardiac tumors. Surgery should be considered to improve the prognosis of patients in good condition with such malignancies and to prevent the occurrence of concomitant critical events.

\section{References}

1. Martínez-Salamanca JI, Huang WC, Millán I, Bertini R, Bianco FJ, Carballido JA, et al. Prognostic impact of the 2009 UICC/AJCC TNM Staging System for Renal Cell Carcinoma with Venous Extension. Eur Urol. 2011;59:120-7.

2. Butany J, Leong SW, Carmichael K, Komeda M. A 30-year analysis of cardiac neoplasms at autopsy. Can J Cardiol. 2005;21:675-80.

3. Roberts WC. Primary and secondary neoplasms of the heart. Am J Cardiol. 1997; 80:671-82.

4. Zustovich F, Gottardo F, De Zorzi L, Cecchetto A, Dal Bianco M, Mauro E, et al. Cardiac metastasis from renal cell carcinoma without inferior vena involvement: a review of the literature based on a case report. Two different patterns of spread? Int J Clin Oncol. 2008;13:271-4.

5. Pala S, Erkol A, Kahveci G. Massive right atrial metastasis from renal cell carcinoma without inferior vena cava involvement. Turk Kardiyol Dern Ars. 2009;37:358.

\title{
Transapical transcatheter aortic valve implantation and off-pump left internal thoracic artery-left anterior descending anastomosis: Back to the future?
}

\author{
Domenico Mazzitelli, MD, Nicolo Piazza, Sabine Bleiziffer, and Ruediger Lange, MD, PhD, \\ Munich, Germany
}

Coronary artery disease can be identified in up to $50 \%$ of patients undergoing transcatheter aortic valve implantation. The management of coronary artery disease in patients

From the Surgery Department, German Heart Center Munich, Munich, Germany. Disclosures: Authors have nothing to disclose with regard to commercial support.

Received for publication March 19, 2011; accepted for publication April 19, 2011; available ahead of print May 19, 2011.

Address for reprints: Domenico Mazzitelli, MD, Cardiovascular Surgery Department, German Heart Center Munich, Lazarettestr. 36, 80636, Munich, Germany (E-mail: mazzitelli@dhm.mhn.de).

J Thorac Cardiovasc Surg 2011;142:e144-6

0022-5223/\$36.00

Copyright (C) 2011 by The American Association for Thoracic Surgery

doi:10.1016/j.jtcvs.2011.04.023 undergoing transcatheter aortic valve implantation is currently a topic of debate. It is currently debated whether the presence of coronary artery disease or nonrevascularized myocardium is associated with an increased risk of adverse events in patients undergoing transcatheter aortic valve implantation.

We report a successful case of concomitant transapical aortic valve implantation and off-pump revascularization of the left anterior descending (LAD) artery via a left small thoracotomy. This procedure, which associates an older technique with a new one, can be an important hybrid strategy for the concomitant treatment of aortic stenosis and coronary artery disease. 